\title{
Current Status of Therapeutic Choice and Feasibility for Patients with Hepatocellular Carcinoma Aged $\geq 70$ Years: A Nationwide Cancer Registry Analysis
}

\author{
Seoung Yoon Rho iD 1,2 \\ Hyun Woong Lee (iD) 2,3 \\ Do Young Kim ${ }^{2,4}$ \\ Kyung Sik Kim ${ }^{2,5}$ \\ 'Department of Surgery, Yongin \\ Severance Hospital, Yonsei University \\ College of Medicine, Seoul, Korea; ${ }^{2}$ The \\ Korean Liver Cancer Association, Seoul, \\ Korea; ${ }^{3}$ Department of Internal Medicine, \\ Gangnam Severance Hospital, Yonsei \\ University College of Medicine, Seoul, \\ Korea; ${ }^{4}$ Department of Internal Medicine, \\ Severance Hospital, Yonsei University \\ College of Medicine, Seoul, Korea; \\ ${ }^{5}$ Department of Surgery, Severance \\ Hospital, Yonsei University College of \\ Medicine, Seoul, Korea
}

Background: The opportunities for examining elderly patients with hepatocellular carcinoma (HCC) have increased. We investigated the treatment of HCC for elderly patients and the overall survival associated with each treatment modality.

Methods: From January 2003 to December 2005 ( $n=578$, period I) and January 2008 to December $2014(\mathrm{n}=2428$, period II), the National Cancer Center and Korean Liver Cancer Association collected clinical data of 3006 patients with HCC aged $\geq 70$ years old at 54 medical centers in Korea. We analyzed the treatment modalities and overall survival for patients with HCC aged $\geq 70$ years.

Results: The mean age, Child-Pugh score, and model for end-stage liver disease score and proportion of male patients were not different between period I and period II (74 years, 6.6, 10.4 and $70.1 \%$ vs 76 years, 6.2, 9.9 and 67.3\%). TNM stage II and BCLC stage A were most commonly noted in periods I and II (44.3\% and $49.1 \%$ vs $40.4 \%$ and $40.2 \%$ ). Transarterial therapy was the most commonly used treatment modality according to age in both periods. Surgical resection was associated with significant superior overall survival compared to local ablation and transarterial therapy $(\mathrm{p}<0.001)$. After propensity score matching between surgical resection and transarterial therapy in period II, surgical resection was associated with more favorable overall survival outcomes (median: 39 months vs 86 months, $\mathrm{p}<0.001)$.

Conclusion: Transarterial therapy was the most commonly used treatment modality for patients with $\mathrm{HCC}$ aged $\geq 70$ years. However, surgical resection led to significantly higher overall survival rates compared to other treatment modalities.

Keywords: hepatocellular carcinoma, elderly, surgical resection, transarterial therapy, local ablation therapy

Correspondence: Kyung Sik Kim Department of Surgery, Severance Hospital, Yonsei University College of Medicine, Ludlow Faculty Research Building, 50-I Yonsei-ro, Seodaemun-gu, Seoul, 03722, Korea

Tel +82-2-2228-2100

Email kskim88@yuhs.ac

Hyun Woong Lee

Department of Internal Medicine, Gangnam Severance Hospital, Yonsei University College of Medicine, 2I I

Eonju-ro, Gangnam-gu, Seoul, 06273, Korea

Tel +82-2-2019-3315

Email LHWDOC@yuhs.ac

\section{ablation therapy}

\section{Introduction}

Hepatocellular carcinoma (HCC) is the fifth most common cancer and second leading cause of cancer related death worldwide. ${ }^{1,2}$ In South Korea, HCC is third most common cancer among gastrointestinal malignancy and the associated mortality rate (14.1\%) was the second highest among all cancer-related deaths in $2016 .{ }^{3}$ The population in South Korea, like that in any other developed country in the world, has rapidly aged. ${ }^{4}$ Among patients who died owing to HCC in 2014, 67.4\% of the patients were aged $>60$ years and $28.5 \%$ of the patients were aged $70-79$ 
years. ${ }^{5}$ It is well known that age is a contributing factor in the development of HCC. ${ }^{6,7}$

It is difficult to define "elderly patients". Despite the ambiguity of the term, it is universally accepted that patients with a chronological age $>65$ years are defined as "elderly patients". With respect to the socioeconomic perspective, such patients are on the verge of retirement. The United Nations and the World Health Organization define individuals aged $>60$ years as "elderly". ${ }^{8}$ In most practical clinical studies, individuals who are "60 years old", "65 years old", or "70 years old" are defined as "elderly". In the 1980 s, researchers mainly defined the age of 65 years as "elderly"; however, the age of 75 years was defined as "elderly" in 90s. In studies involving a Japanese group, individuals aged $>80$ years were defined as the "super-elderly population". ${ }^{10-13}$

In previous studies on elderly patients with $\mathrm{HCC}$ in South Korea, researchers defined "elderly patient" as patients aged $>$ over 65 or 70 years and investigated the treatment modalities and outcomes. However, these studies were confined to single centers, and it was difficult to reflect the trends or the outcomes of treatment in elderly patients with HCC nationwide using these data. ${ }^{14-16}$ To overcome these limitations and to aid in establishing a nationwide treatment strategy for elderly patients with HCC, we aimed to evaluate the therapeutic modalities used to treat patients with $\mathrm{HCC}$ aged $>70$ years in detail and to compare the overall survival associated with each treatment modality using data from the National Cancer Center (NCC) and the Korean Liver Cancer Association (KLCA).

\section{Patients and Methods}

\section{The Korean Central Cancer Registry}

The Korean Central Cancer Registry (KCCR), a nationwide cancer registry, was developed by the Ministry of Health and Welfare, South Korea. Using code C22.0, which defines HCC, of the International Classification of Disease 10th edition (ICD-10) coding system, patients with HCC were identified in the KCCR registry. From January 2003 to December 2005 (period I) and January 2008 to December 2014 (period II), the NCC and KLCA collected the clinical data of 3006 patients with $\mathrm{HCC}$ aged $>70$ years from 54 medical centers in South Korea archived in the KCCR. New patients are enrolled in the cancer registry each year.

During 2003-2005 (period I), the KLCA collected the medical data from each tertiary medical center in South Korea. During that period, patients' medical records from each medical center were voluntarily added in the database as the initial prototype of the cancer registry. After three years of preparation, the KCCR was started in collaboration with the NCC, and medical recorders were dispatched to each medical center to collect the patient data.

\section{Study Population and Study Design}

Using these data, we analyzed the rates of use of and overall survival associated with each treatment modality for patients with HCC aged $>70$ years. All the treatment modality is recorded as "initial treatment" for the patients. We obtained the patients' mortality data from the Korean National Statistics Office (KNSO). The initial treatment dates and dates of disease progression were obtained from the KCCR records. To investigate the nationwide distribution of each treatment modality, we divided the patients into three groups (ages 70-75 years, aged 76-80 years, and aged $>80$ years). The follow-up durations were estimated from the date of initial treatment to date of death or were calculated to a certain date for each period (December 31, 2011 for period I and December 31, 2016 for period II) for the analysis of overall survival.

In this study, the treatment modalities were classified as surgical resection, local ablation therapy, transarterial therapy, chemotherapy, radiation therapy, no treatment, and unknown. Local ablation therapy included radiofrequency ablation (RFA), percutaneous ethanol injection, and cryoablation. Transarterial therapy included transarterial chemoembolization (TACE) with gelatin sponge, TACE with DC Beads ${ }^{\mathrm{TM}}$ (Biocompatibles Ltd, Farnham, UK) or HepaSphere ${ }^{\mathrm{TM}}$ (Biosphere Medical, Rockland, MA), transarterial chemolipiodolization, transarterial chemoinfusion, and transarterial radioembolization (Yt-90). We retrospectively reviewed the medical records of each patient. This study was approved by the internal review board of Severance Hospital (IRB No. 4-2018-0354) and conducted according to the principles of the Declaration of Helsinki. Informed consent was obtained by the NCC and KLCA, and the collection of data was approved by each participating medical center or institution.

\section{Statistical Analysis and Propensity Score Matching (PSM)}

Descriptive analyses of the clinical data were performed using the Student's $t$-test and Pearson's chi-square test. The overall survival time was analyzed using the KaplanMeier method, and statistical differences were verified using Log rank tests. Statistical significance was set at 
$\mathrm{p}<0.05$. All results were reported as the mean with standard deviation or percentages. Propensity score matching (PSM) was performed, with the caliper set at 0.2. To reduce selection bias and the effects of potential confounders, the propensity score was calculated using logistic regression based on age, sex, etiology, Child-Pugh score, and Barcelona Clinic Liver Cancer (BCLC) stage. Differences between the two groups were balanced using 1:1 PSM analysis. All statistical analyses were performed using SPSS $^{\circledR}$ for Windows version 22.0 (IBM Corp., Armonk, NY, USA) and R version 3.3.1 (The R Project, Vienna, Austria).

\section{Results}

\section{Clinical Characteristics in Patients with HCC}

Period I included 578 patients with a mean age of 74 years. Of the patients included in this period, 405 (70.1\%) were men, 152 (26.3\%) had hepatitis B, and $162(28.0 \%)$ had hepatitis C. The mean Child-Pugh score (CPS) was 6.6, and the mean model for endstage liver disease (MELD) score was 10.4. More than $60 \%$ of the patients were classified as having ChildPugh class A disease and 256 patients (44.3\%) were classified as having TNM stage II stage, while 160 patients $(27.7 \%)$ were classified as having TNM stage III disease. Nearly half of the patients were classified as having BCLC stage A disease (284 patients; 49.1\%); 93 (16.1\%), BCLC stage B disease; and 129 (22.3\%), BCLC stage $\mathrm{C}$ disease.

Period II included 2428 patients with a mean age of 76 years. Of the patients included in this period, $1633(67.3 \%)$ were men, 587 (24.2\%) had hepatitis B, and 552 (22.7\%) had hepatitis C. The mean alpha-fetoprotein (AFP) level was $5817 \pm 876 \mathrm{ng} / \mathrm{mL}$, and the mean protein induced by vitamin $\mathrm{K}$ absence or antagonist-II (PIVKA-II) level was $5208 \pm 550$ $\mathrm{mAu} / \mathrm{mL}$. The mean CPS was 6.2, and the mean MELD score was 9.9. This period included 980 patients (40.4\%) classified as having TNM stage II disease and 692 patients (28.5\%) with TNM stage III disease. The BCLC classification of the patients was as follows: 977 patients $(40.2 \%)$, stage A disease; 382 patients (15.7\%), stage B disease; and 775 patients $(32.0 \%)$, stage C (Table 1$)$.
Table I Clinical Characteristics of the Patients with Hepatocellular Carcinoma

\begin{tabular}{|c|c|c|}
\hline Variables & $\begin{array}{c}\text { Period } \\
\text { I (2003-2005) }\end{array}$ & $\begin{array}{c}\text { Period II } \\
(2008-2014)\end{array}$ \\
\hline & $\mathrm{N}=578$ & $N=2428$ \\
\hline Age & $74 \pm 4$ & $76 \pm 5$ \\
\hline Gender, male:female & 405:I73 (70.1:29.9) & 1633:795 (67.3:32.7) \\
\hline BMI $\left(\mathrm{kg} / \mathrm{m}^{2}\right)$ & Not checked & $23.4 \pm 3.5$ \\
\hline $\begin{array}{l}\text { Etiology (\%) } \\
\text { HBV } \\
\text { HCV } \\
\text { HBV and HCV } \\
\text { Alcohol } \\
\text { Unknown }\end{array}$ & $\begin{array}{l}152(26.3) \\
162(28.0) \\
5(0.9) \\
77(13.3) \\
182(31.5)\end{array}$ & $\begin{array}{c}587(24.2) \\
552(22.7) \\
18(0.7) \\
464(19.1) \\
807(33.2)\end{array}$ \\
\hline Diabetes & Not checked & $822(33.9)$ \\
\hline Hypertension & Not checked & $1299(53.5)$ \\
\hline $\begin{array}{l}\text { ECOG performance } \\
0 \\
1 \\
2 \\
3 \\
4 \\
\text { Unknown }\end{array}$ & Not checked & $\begin{array}{c}1082(44.6) \\
297(12.2) \\
104(4.3) \\
44(1.8) \\
24(1.0) \\
879(36.1 \%)\end{array}$ \\
\hline $\begin{array}{l}\text { Hepatic } \\
\text { encephalopathy } \\
\text { None } \\
\text { Grade I-2 } \\
\text { Grade 3-4 }\end{array}$ & $\begin{array}{c}557(96.4) \\
13(2.2) \\
8(1.4)\end{array}$ & $\begin{array}{c}2360(97.1) \\
60(2.5) \\
9(0.4)\end{array}$ \\
\hline $\begin{array}{l}\text { Ascites (\%) } \\
\text { None } \\
\text { Slight } \\
\text { Moderate to severe }\end{array}$ & $\begin{array}{l}40 \mathrm{I}(69.4) \\
112(19.4) \\
65(11.2)\end{array}$ & $\begin{array}{c}1830(75.4) \\
369(15.2) \\
229(9.4)\end{array}$ \\
\hline $\operatorname{AFP}(\mathrm{ng} / \mathrm{mL})$ & Not checked & $5817 \pm 876$ \\
\hline PIVKA-II (mAu/mL) & Not checked & $5208 \pm 550$ \\
\hline Child-Pugh score & $6.6 \pm 1.8$ & $6.2 \pm 1.5$ \\
\hline $\begin{array}{l}\text { Child-Pugh } \\
\text { classification } \\
\text { A } \\
\text { B } \\
\text { C } \\
\text { Unknown }\end{array}$ & $\begin{array}{c}357(6 \mid .8) \\
177(30.6) \\
44(7.6)\end{array}$ & $\begin{array}{c}1625(66.9) \\
594(24.5) \\
98(4.0) \\
111(4.6)\end{array}$ \\
\hline MELD score & $10.4 \pm 4.2$ & $9.9 \pm 4.0$ \\
\hline
\end{tabular}

(Continued) 
Table I (Continued).

\begin{tabular}{|l|c|c|}
\hline Variables & $\begin{array}{c}\text { Period } \\
\text { I (2003-2005) }\end{array}$ & $\begin{array}{c}\text { Period II } \\
(\mathbf{2 0 0 8 - 2 0 I 4 )}\end{array}$ \\
\hline TNM stage & & \\
I & $35(6.0)$ & $285(I 1.7)$ \\
II & $256(44.3)$ & $980(40.4)$ \\
III & $160(27.7)$ & $692(28.5)$ \\
IV-A & $52(9.0)$ & $238(9.8)$ \\
IV-B & $49(8.5)$ & $223(9.2)$ \\
Unknown & $26(4.5)$ & $9(0.4)$ \\
\hline BCLC stage & & \\
0 & $25(4.3)$ & $132(5.4)$ \\
A & $284(49.1)$ & $977(40.2)$ \\
B & $93(16.1)$ & $382(15.7)$ \\
C & $129(22.3)$ & $775(32.0)$ \\
D & $47(8.2)$ & $162(6.7)$ \\
\hline
\end{tabular}

Note: Data are reported as mean \pm standard deviation or $n(\%)$.

Abbreviations: HBV, hepatitis B; HCV, hepatitis C; ECOG, Eastern Cooperative Oncology Group; AFP, alpha-fetoprotein; PIVKA-II, proteins induced by vitamin $\mathrm{K}$ absence or antagonist-II; MELD, model for end-stage liver disease; BCLC, Barcelona clinic liver cancer; BMI, body mass index.

\section{Treatment Distribution According to Age}

Transarterial therapy was the most commonly used treatment modality for patients in period I ( $\mathrm{n}=284$ patients,
$49.1 \%)$. This treatment modality was used in $52.8 \%$ of the patients aged $70-75$ years, $43.3 \%$ of the patients aged $76-80$ years, and $38.3 \%$ of the patients aged $>80$ years. Surgical resection and local ablation therapy were each used in $6.3 \%$ of the patients aged $70-75$ years.

Transarterial therapy was the most commonly used treatment modality for patients in period II ( $\mathrm{n}=1079$ patients, $44.4 \%$ ). This treatment modality was used in $47.1 \%$ of the patients aged $70-75$ years and $34.0 \%$ of the patients aged $>$ 80 years. Surgical ablation was used in $14.5 \%$ of the patients aged $70-75$ years and $3.7 \%$ of the patients aged $>80$ years. Among patients aged $70-75$ years, 281 patients (20.2\%) did not receive treatment, while 179 patients $(47.2 \%)$ aged $>80$ years did not receive treatment (Table 2).

\section{Overall Survival Analysis According to Treatment Modality}

The overall survival was significantly longer for patients who underwent surgical resection in period I $(n=29$, median survival: 81 months) than that for those who underwent local ablation therapy ( $\mathrm{n}=41$, median survival: 45 months) and transarterial therapy ( $\mathrm{n}=284$, median survival: 23 months; $\mathrm{p}<0.001$; Figure 1).

Table 2 Treatment Distribution According to Age

\begin{tabular}{|c|c|c|c|c|c|c|c|c|}
\hline \multicolumn{9}{|c|}{ A. Period I (2003-2005) } \\
\hline \multirow[t]{2}{*}{ Treatment Modality } & & \multirow[t]{2}{*}{ Total $(\mathbf{N}=578)$} & \multicolumn{6}{|c|}{ Age } \\
\hline & & & 70-75 ( & $N=379)$ & $76-80(N=152)$ & $>80(\mathrm{~N}=47)$ & & alue \\
\hline \multirow{2}{*}{\multicolumn{2}{|c|}{ Surgical resection }} & $29(5.0)$ & \multicolumn{2}{|c|}{$24(6.3)$} & $4(2.6)$ & I (2.I) & \multicolumn{2}{|c|}{0.119} \\
\hline & & $4 I(7 . I)$ & \multicolumn{2}{|c|}{$24(6.3)$} & $12(7.9)$ & $5(10.6)$ & & \\
\hline \multicolumn{2}{|l|}{ Transarterial therapy } & $284(49.1)$ & \multicolumn{2}{|c|}{$200(52.8)$} & $66(43.4)$ & $18(38.3)$ & & \\
\hline Systemic chemotherapy & \multicolumn{2}{|c|}{ I $(0.2)$} & \multicolumn{2}{|c|}{ I $(0.3)$} & $0(0)$ & $0(0)$ & & \\
\hline Radiation therapy & & $7(1.2)$ & \multicolumn{2}{|c|}{4 (I.I) } & $3(2.0)$ & $0(0)$ & & \\
\hline Unknown & \multicolumn{2}{|c|}{$216(37.4)$} & \multicolumn{2}{|c|}{$126(33.2)$} & $67(44.1)$ & $23(48.9)$ & & \\
\hline \multicolumn{9}{|c|}{ B. Period II (2008-20I4) } \\
\hline \multirow[t]{2}{*}{ Treatment Modality } & \multirow[t]{2}{*}{ Total $(\mathrm{N}=2428)$} & \multicolumn{7}{|c|}{ Age } \\
\hline & & \multicolumn{2}{|c|}{$70-75(N=1393)$} & & $76-80(N=656)$ & \multicolumn{2}{|c|}{$>80(\mathrm{~N}=379)$} & p-value \\
\hline Surgical resection & $255(10.5)$ & \multicolumn{2}{|c|}{$202(14.5)$} & & $39(5.9)$ & 14 & & 0.159 \\
\hline Local ablation therapy & $255(10.5)$ & 167 & $(12.0)$ & & $66(10.1)$ & 22 & & \\
\hline Transarterial therapy & $1079(44.4)$ & 655 & $(47.1)$ & & $295(45.0)$ & 129 & & \\
\hline Systemic chemotherapy & $88(3.6)$ & & (3.4) & & $24(3.7)$ & 16 & & \\
\hline Radiation therapy & $22(0.9)$ & & (0.9) & & $7(1.1)$ & 3( & & \\
\hline No treatment & $667(27.5)$ & 281 & (20.2) & & $207(31.6)$ & 179 & & \\
\hline Unknown & $62(2.6)$ & & (2.0) & & $18(2.7)$ & & & \\
\hline
\end{tabular}

Note: Data are reported as mean \pm standard deviation or $\mathrm{n}(\%)$. 


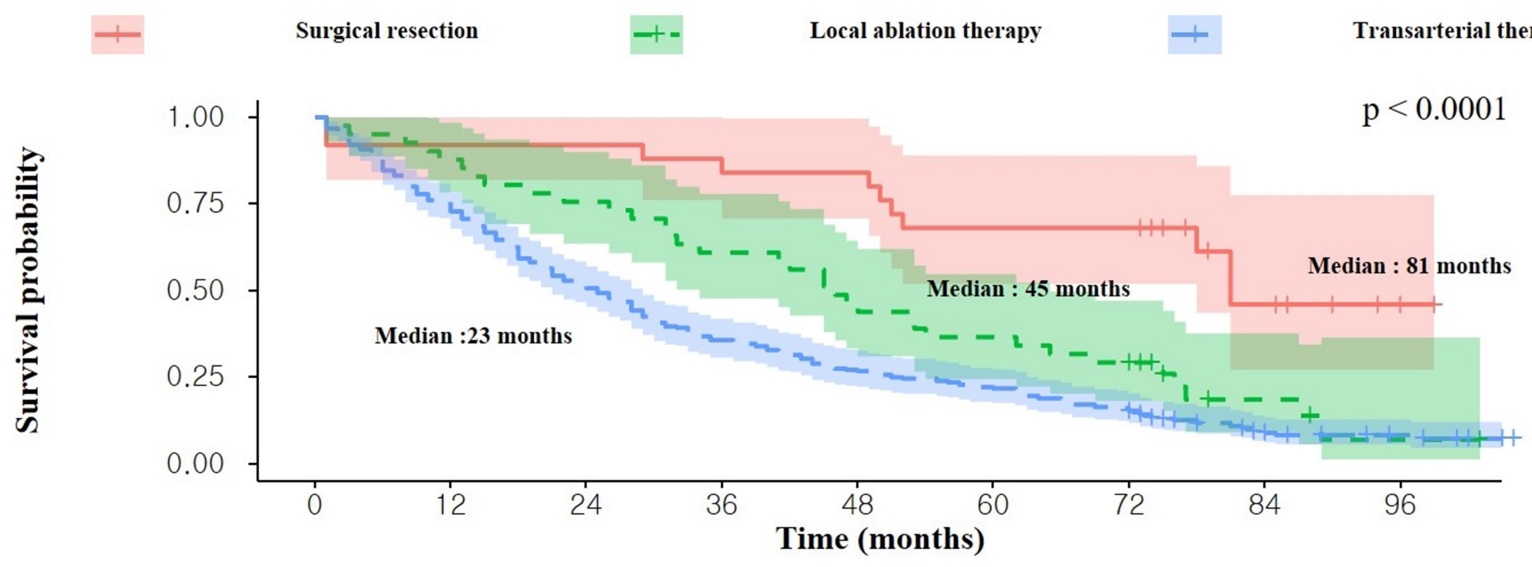

Number at risk

$\begin{gathered}\text { Surgical resection } \\
\text { Local ablation therapy } \\
\text { Transarterial therapy }\end{gathered}-$\begin{tabular}{cccccccccc}
29 & 23 & 23 & 22 & 21 & 17 & 17 & 6 & 2 \\
41 & 36 & 31 & 25 & 19 & 15 & 12 & 4 & 1 \\
284 & 212 & 146 & 100 & 76 & 62 & 45 & 18 & 8 \\
\hline 0 & 12 & 24 & 36 & 48 & 60 & 72 & 84 & 96
\end{tabular}

Figure I Overall survival according to the treatment modality used in period I (2003-2005). The overall survival was significantly longer for patients who underwent surgical resection in period I than that for those who underwent local ablation therapy and transarterial therapy.

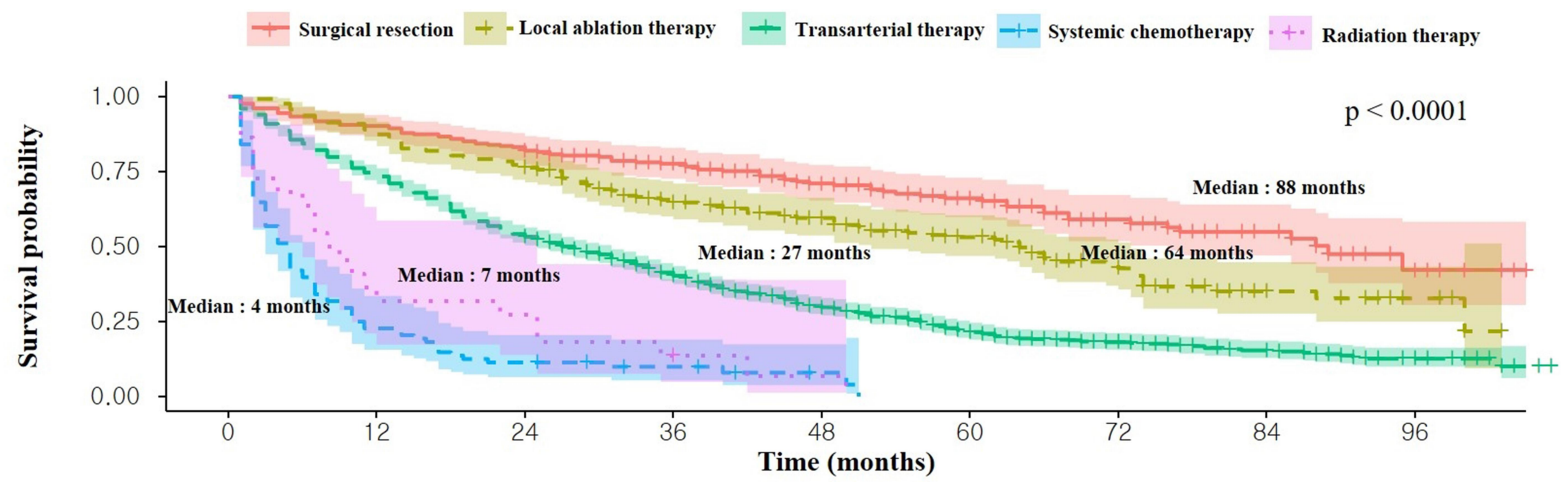

Number at risk

\begin{tabular}{|c|c|c|c|c|c|c|c|c|c|}
\hline Surgical resection & 255 & 230 & 212 & 161 & 112 & 80 & 46 & 27 & 8 \\
\hline Local ablation therapy & 255 & 227 & 197 & 139 & 104 & 69 & 39 & 16 & 6 \\
\hline Transarterial therapy & 1079 & 806 & 585 & 387 & 234 & 132 & 79 & 40 & 15 \\
\hline Systemic chemotherapy & 88 & 20 & 10 & 6 & 2 & 0 & 0 & 0 & 0 \\
\hline \multirow[t]{2}{*}{ Radiation therapy } & 22 & 8 & 6 & 3 & 1 & 0 & 0 & 0 & 0 \\
\hline & 0 & 12 & 24 & 36 & 48 & 60 & 72 & 84 & 96 \\
\hline
\end{tabular}

Figure 2 Overall survival according to the treatment modality used in period II (2008-20I4). The overall survival was significantly longer for patients who underwent surgical resection in period II than for those who received other therapeutic modalities, followed by local ablation therapy, transarterial therapy, radiation therapy, and systemic chemotherapy.

The overall survival was significantly longer for patients who underwent surgical resection $(n=255$, median survival: 88 months; $\mathrm{p}<0.001)$ in period II than for those who received other therapeutic modalities, followed by local ablation therapy ( $\mathrm{n}=255$, median survival: 64 months), transarterial therapy ( $\mathrm{n}=1079$, median survival: 
Table 3 Clinical Characteristics After Propensity Score Matching Between Surgical Resection and Transarterial Therapy in Period II (2008-20I4)

\begin{tabular}{|c|c|c|c|}
\hline Variables & $\begin{array}{l}\text { Surgical } \\
\text { Resection } \\
(\mathrm{N}=\mathbf{2 4 7})\end{array}$ & $\begin{array}{l}\text { Transarterial } \\
\text { Therapy }(n=247)\end{array}$ & P-value \\
\hline Age & $74 \pm 4$ & $74 \pm 3$ & 0.910 \\
\hline $\begin{array}{l}\text { Gender, } \\
\text { male }\end{array}$ & I83 (74.I) & $193(78.1)$ & 0.342 \\
\hline $\begin{array}{l}\text { Etiology } \\
\text { HBV } \\
\text { HCV } \\
\text { HBV and } \\
\text { HCV } \\
\text { Alcohol } \\
\text { Unknown }\end{array}$ & $\begin{array}{l}62(25.1) \\
46(18.6) \\
1(0.4) \\
55(22.3) \\
83(33.6)\end{array}$ & $\begin{array}{l}67(27.1) \\
50(20.2) \\
2(0.8) \\
51(20.6) \\
77(31.2)\end{array}$ & 0.899 \\
\hline $\begin{array}{l}\text { ECOG } \\
\text { performance } \\
0 \\
1 \\
2 \\
\text { Unknown }\end{array}$ & $\begin{array}{l}|5|(6|.|) \\
4 \mid(\mid 6.6) \\
5(2.0) \\
50(20.2)\end{array}$ & $\begin{array}{l}153(6 \mid .9) \\
22(8.9) \\
6(2.4) \\
50(20.2)\end{array}$ & 0.062 \\
\hline $\begin{array}{l}\text { AFP }(\mathrm{ng} / \mathrm{mL}) \\
\text { PIVKA } \\
(\mathrm{mAu} / \mathrm{mL})\end{array}$ & $\begin{array}{l}\mid 806 \pm 831 \\
3253 \pm 688\end{array}$ & $\begin{array}{l}2102 \pm 741 \\
2812 \pm 733\end{array}$ & $\begin{array}{l}0.791 \\
0.662\end{array}$ \\
\hline $\begin{array}{l}\text { Child-Pugh } \\
\text { score }\end{array}$ & $5.3 \pm 0.7$ & $5.3 \pm 0.6$ & 0.684 \\
\hline MELD score & $8.0 \pm 2.2$ & $8.6 \pm 2.3$ & 0.012 \\
\hline $\begin{array}{l}\text { TNM Stage } \\
\text { Stage I } \\
\text { Stage II } \\
\text { Stage III } \\
\text { Stage IV-A } \\
\text { Stage IV-B }\end{array}$ & $\begin{array}{l}18(7.3) \\
182(73.3) \\
42(17.0) \\
2(0.8) \\
3(1.2 \%)\end{array}$ & $\begin{array}{l}19(7.7) \\
170(68.8) \\
51(20.6) \\
5(2.0) \\
2(0.8)\end{array}$ & 0.512 \\
\hline $\begin{array}{l}\text { BCLC stage } \\
\text { O } \\
\text { A } \\
\text { B } \\
\text { C } \\
\text { D }\end{array}$ & $\begin{array}{l}\text { I5I (6I.I) } \\
4 I(16.6) \\
54(21.9) \\
I(0.4) \\
0(0)\end{array}$ & $\begin{array}{l}\text { I } 43(57.9) \\
35(14.2) \\
68(27.5) \\
\text { I }(0.4) \\
0(0)\end{array}$ & 0.087 \\
\hline
\end{tabular}

Note: Data are reported as mean \pm standard deviation or $n(\%)$. Abbreviations: HBV, hepatitis B; HCV, hepatitis C; ECOG, Eastern Cooperative Oncology Group; AFP, alpha-fetoprotein; PIVKA-II, proteins induced by vitamin $\mathrm{K}$ absence or antagonist-II; MELD, model for end-stage liver disease; BCLC, Barcelona clinic liver cancer.

27 months), radiation therapy ( $\mathrm{n}=22$, median survival: 7 months), and systemic chemotherapy ( $\mathrm{n}=88$, median survival: 4 months; Figure 2). Among 88 patients who received systemic therapy including sorafenib, 66 patients were categorized as BCLC C. In the BCLC C category, 57 patients treated by sorafenib as initial therapy for the HCC.

\section{Subgroups Analysis of Overall Survival According to BCLC Stage and Treatment Modality in Each Period}

The overall survival according to the BCLC stage in both periods was significantly longer in the order of BCLC stage 0, A, B, C and D. Between each stage, there were statistically significant differences. In the comparison of median survival at the same BCLC stages in both periods, there was no significant differences in BCLC stage D. However, in the early stage of HCC especially BCLC stage 0 and A, the median survival of period II increased more than 10 months compared to period I. (BCLC stage 0: 63 months vs 53 months) (BCLC stage A: 37 months vs 27 months) (Supplement Figure S1, Supplement Figure S2). In the subgroup analysis of overall survival according to BCLC stage and treatment modality in each period, more various treatments were attempted even in the advanced stage such BCLC stage C and D in period II compared to period I. (Supplement Figure S3, Supplement Figure S4).

\section{PSM Between Surgical Resection and Transarterial Therapy}

After 1:1 PSM, 247 patients who underwent surgical resection were matched with 247 patients who underwent transarterial therapy. There were no significant differences with respect to age, gender, etiology, performance status, AFP level, PIVKAII level, CPS, TNM stage and BCLC stage between the surgical resection and transarterial therapy groups. Only the MELD score (8.6) of the transarterial therapy group was significantly higher than that of the surgical resection group (8.0; $\mathrm{p}=0.012$ ). TNM stage II was most common in both groups (surgical resection: 73.3\%; transarterial therapy: $68.8 \%$ ). Stage $\mathrm{O}$ was the most common BCLC stage in both groups (surgical resection: 61.1\%; transarterial therapy: 57.9\%; Table 3). Survival analysis after PSM revealed that the overall survival was significantly longer for patients who underwent surgical resection (median survival: 86 months) than the matched patients who underwent transarterial therapy (median survival: 39 months; $\mathrm{p}<0.005$; Figure 3 ). 

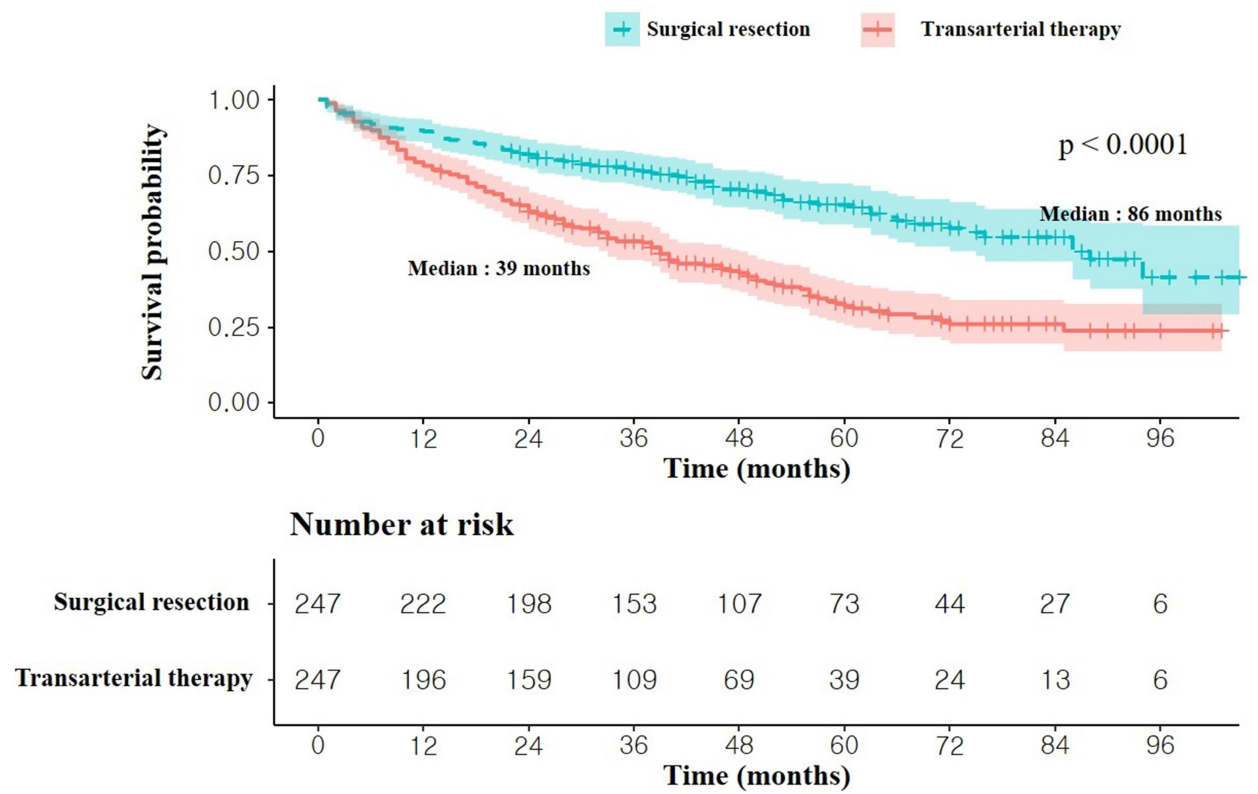

Figure 3 Overall survival analysis after PSM between the two groups in period II (2008-2014). Survival analysis after PSM revealed that the overall survival was significantly longer for patients who underwent surgical resection than the matched patients who underwent transarterial therapy.

\section{PSM Between Surgical Resection and Local Ablation Therapy in Early HCC}

After PSM, 87 patients of surgical resection and local ablation therapy were compared, respectively. Only patients in BCLC stage 0 and A were included. There were no significant differences in terms of age, gender, etiology, performance status, AFP level, MELD score (Table 4). In overall survival analysis after PSM, there was a significant benefit for patients who underwent surgical resection (median survival: 88 months) than the patients who underwent local ablation therapy (median survival: 65 months, $\mathrm{p}=0.036$ ) (Figure 4).

\section{Prognostic Factors in Each Period}

In the univariate and multivariate cox-regression analysis of overall survival, the BCLC stage and treatment modality were significant prognostic factors in both periods. In period I, female, hepatitis $\mathrm{C}$ infection and hepatic encephalopathy were significant prognostic factors. Whereas, old age, AFP, PIVKA level, and the high Child-Pugh score were poor prognostic factors for overall survival in period II. (Table 5).

\section{Discussion}

As patients age, the risk of drug-induced injuries, critical viral hepatitis, and intra-abdominal sepsis in the liver increases. ${ }^{17}$ The incidence of HCC in elderly patients reflects these risks. Hepatitis is the most potent predisposing factor for HCC, and the incidence of hepatitis $\mathrm{C}$ among patients aged $>60$ years has increased rapidly in South Korea. ${ }^{18}$ The incidence of non-hepatitis B- and non-hepatitis C-related HCC (NBNC-HCC) is also significantly higher among the elderly patients. Katsuta et al reported that the incidence of NBNC-HCC is significantly higher in patients aged $>80$ years than in younger patients. ${ }^{10}$ In elderly patients, HCC frequently develops in the normal liver without cirrhosis or fibrosis. Paradis et al reported that the incidence of HCC without liver fibrosis was higher in patients with metabolic syndrome than in those with chronic liver injuries due to other causes. ${ }^{19}$ Satyanarayana et al and Plentz et al have both reported that shortened telomere lengths owing to aging deplete the ability to regenerate the liver and that liver cirrhosis and loss of P53 accelerate the telomere dysfunction, resulting in the development of $\mathrm{HCC} .^{20,21}$

Knowledge of these pathophysiological changes in the liver is important when treating HCC in elderly patients. Most importantly, the risks and benefits of any treatment modality should be assessed prior to administering it to the elderly patients with HCC. The benefit of the treatment should be greater than the decrease in survival owing to the treatment and maladjustments resulting from physical or mental stress. As most elderly patients have comorbidities, effective treatment strategies must be identified using 
Table 4 Clinical Characteristics After Propensity Score Matching Between Surgical Resection and Local Ablation Therapy for Early Stage Hepatocellular Carcinoma in Period II (2008-20I4)

\begin{tabular}{|c|c|c|c|}
\hline \multirow[t]{2}{*}{ Variables } & $\begin{array}{l}\text { Surgical } \\
\text { Resection }\end{array}$ & $\begin{array}{l}\text { Local } \\
\text { Ablation }\end{array}$ & P-value \\
\hline & $(\mathrm{N}=87)$ & $(\mathbf{N}=87)$ & \\
\hline Age & $73.8 \pm 3.6$ & $74.0 \pm 3.7$ & 0.695 \\
\hline Gender, male & $60(69.0 \%)$ & 61 (70.1\%) & 1.000 \\
\hline $\begin{array}{l}\text { Etiology } \\
\text { HBV } \\
\text { HCV } \\
\text { Alcohol } \\
\text { Unknown }\end{array}$ & $\begin{array}{l}25(28.7 \%) \\
19(21.8 \%) \\
17(19.5 \%) \\
26(29.9 \%)\end{array}$ & $\begin{array}{l}20(23.0 \%) \\
26(29.9 \%) \\
18(20.7 \%) \\
23(26.4 \%)\end{array}$ & 0.603 \\
\hline $\begin{array}{l}\text { ECOG performance } \\
0 \\
\text { Unknown }\end{array}$ & $\begin{array}{l}64(73.6 \%) \\
23(26.4 \%)\end{array}$ & $\begin{array}{l}66(75.9 \%) \\
21(24.1 \%)\end{array}$ & 0.862 \\
\hline AFP $(\mathrm{ng} / \mathrm{mL})$ & $73.7 \pm 220.1$ & $94.8 \pm 298.7$ & 0.596 \\
\hline $\begin{array}{l}\text { Child-Pugh } \\
\text { Classification } \\
\text { A } \\
\text { B }\end{array}$ & $\begin{array}{l}84(96.6 \%) \\
3(3.4 \%)\end{array}$ & $\begin{array}{l}82(94.3 \%) \\
5(5.7 \%)\end{array}$ & 0.717 \\
\hline MELD score & $7.9 \pm 1.6$ & $8.1 \pm 1.7$ & 0.440 \\
\hline $\begin{array}{l}\text { BCLC stage } \\
\text { O } \\
\text { A }\end{array}$ & $\begin{array}{l}10(11.5 \%) \\
77 \text { (88.5\%) }\end{array}$ & $\begin{array}{l}\text { I3 (I4.9\%) } \\
74(85.1 \%)\end{array}$ & 0.654 \\
\hline
\end{tabular}

Note: Data are reported as mean \pm standard deviation or $n(\%)$.

Abbreviations: HBV, hepatitis B; HCV, hepatitis C; ECOG, Eastern Cooperative Oncology Group; AFP, alpha-fetoprotein; MELD, model for end-stage liver disease; BCLC, Barcelona clinic liver cancer.

a more systematic approach that includes the evaluation of rehabilitation and long-term care.

In this study, we identified the rate of use of different therapeutic modalities and the changes noted in the therapeutic modalities used for treating HCC in elderly patients over time. In period I, only $5.0 \%$ of the patients underwent surgical resection, and unspecified modalities (including no treatment) were used for $37.4 \%$ of the patients. In period II, $10.5 \%$ of the patients underwent surgical resection, and unspecified methods (including no treatment) were used for only $30.1 \%$ of the patients. This shift indicates that biological age is not the only factor used to determine the indication for aggressive treatment. However, in patients aged $>80$ years, the rate of use of unspecified methods (including no treatment) was stable (period I: $48.9 \%$; period II: $51.4 \%$ ).

Kaplan-Meier analysis revealed that the longest overall survival was noted for patients who underwent surgical resection, followed by patients who underwent local ablation therapy and transarterial therapy. In the subgroup analysis of overall survival according to BCLC stage and treatment modality in each period, BCLC stage 0 and A showed better survival with statistical significance compared to other advanced stages in both periods. In addition, more various treatment modalities were attempted in period II compared to period I, the median survival increased by more than 10 months in early BCLC stages ( 0 and A).

PSM was performed to compare the therapeutic effects between the surgical resection group, which is considered the most radical treatment, and the transarterial therapy group, which is the most widely used treatment modality for elderly patients. Surgical resection was associated with a statistically significant overall survival benefit compared to transarterial therapy. Furthermore, in overall survival analysis of early HCC including BCLC stage 0 and A only, surgical resection showed statistically significant benefit compared to local ablation therapy after PSM. There is still a debating the issue in terms of treating the small early HCC by local ablation therapy. ${ }^{22-26}$ This present study supported the evidence that surgical resection is preferred in treating the small early $\mathrm{HCC}$ even in elderly patients. This is probably due to several reasons. First, this database included all anatomical resection and nonanatomical resection. Second, because surgical methods well-established recently, perioperative mortality of the "elderly patients" was extremely low. In addition, unlike the SURF trial, this study is only focused on only "elderly patients". Thus, it is possible that more "healthy patients" who cannot be subdivided by ECOG performance criteria had become candidates for surgical resection.

In the analysis of prognostic factors for overall survival, the BCLC stage and treatment modality were significant commonly in both periods. The old age, AFP, PIVKA level, and the high Child-Pugh score were poor prognostic factors in period II. These are the same prognostic factors that affect the overall survival even in the general population group as well as elderly patients.

According to the Korea Practice Guideline for the Management of HCC, surgical resection is the primary treatment for solitary HCC without liver cirrhosis and for patients with cirrhosis who are expected to have sufficient residual liver function after surgical resection. ${ }^{27}$ In elderly patients, resection should be considered carefully, as the capacity for liver regeneration is compromised. Currently, detailed guidelines are not available for the treatment of HCC in elderly patients, although several studies have 

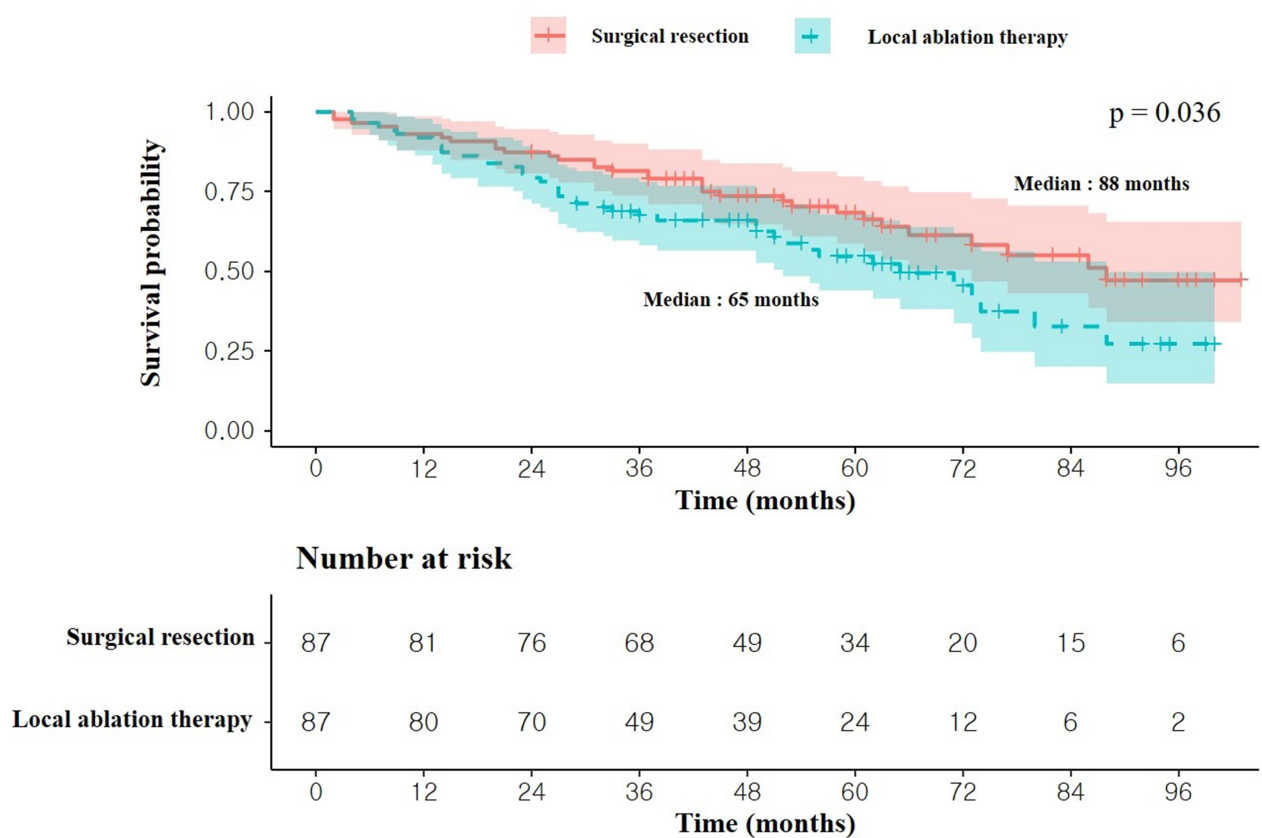

Figure 4 Overall survival analysis after PSM between surgical resection and radiofrequency ablation groups for early stage hepatocellular carcinoma in period II (2008-2014). Survival analysis after PSM revealed that the overall survival was significantly longer for patients who underwent surgical resection than the matched patients who underwent local ablation therapy.

Abbreviation: PSM, propensity score matching.

reported comparable outcomes of surgical resection in elderly HCC patients. In many studies, aggressive treatment, such as surgical resection, is beneficial for elderly patients without critical comorbidities, such as cardiovascular disease. Iida et al compared the outcomes of 44 patients with $\mathrm{HCC}$ aged $>80$ years and 351 patients with HCC aged $<80$ years who underwent surgical resection and found no significant differences between the two groups with respect to the overall or disease-free survival. However, postoperative complications were found to significantly affect the overall survival of the patients aged $>80$ years in multivariate regression analysis (Nutrient status was identified potent cause of postoperative complications, and the authors emphasized on perioperative nutritional support. ${ }^{11} \mathrm{Kim}$ et al reported that the incidence of postoperative pneumonia was significantly higher in patients aged $>70$ years old than in patients aged 60-69 years. ${ }^{28}$ Kishida et al also reported that the postoperative complication rate $(\geq$ Clavien-Dindo classification grade III) was significantly higher in patients aged $>75$ years old compared patients aged $<75$ years old. ${ }^{29}$ Kaibori et al used data from the Liver Cancer Study Group of Japan to analyze the overall survival of 12,587 patients with HCC who underwent hepatectomy. The patients were divided into three groups (aged > 75 years: 2020 patients; aged 60-74 years: 7576 patients; and aged 40-59 years: 2991 patients). They found that the overall survival of patients aged $>75$ years was significantly lesser than that of the patients in the other groups but that the disease-free survival of the three groups was not significantly different. ${ }^{30}$ Therefore, limited resection should be performed in consideration of the regeneration capacity of the liver. Perioperative nutritional support should be provided and efforts should be made to prevent the development postoperative infections.

When surgical resection cannot be performed, RFA and TACE are the good alternative therapeutic strategies. Previous studies compared the overall survival of patients aged $>75$ years and patients aged $<75$ years who underwent RFA and found no significant difference in the overall survival between the two matched groups. ${ }^{31,32}$ Yau et al reported that the disease-free specific survival was significantly longer in patients aged $>70$ years who underwent TACE than in those aged $<70$ years who underwent TACE).$^{33}$ In contrast, Mirici-Cappa et al found no significant differences in the overall survival between patients aged $>70$ years and patients aged $<70$ years who were matched using PSM. ${ }^{34}$ These studies indicate that RFA 
Table 5 Multivariate Cox-Regression Analysis in Each Period

\begin{tabular}{|c|c|c|c|c|c|c|}
\hline \multirow[b]{2}{*}{ Variables } & \multicolumn{3}{|l|}{ Period I } & \multicolumn{3}{|c|}{ Period II } \\
\hline & p-value & HR & $95 \% \mathrm{Cl}$ & p-value & HR & $95 \% \mathrm{Cl}$ \\
\hline Age & 0.167 & 1.019 & $0.992-1.046$ & 0.004 & 1.026 & $1.009-1.044$ \\
\hline Gender (female) & 0.018 & $0.77 \mid$ & $0.62 I-0.955$ & 0.460 & 1.072 & $0.891-1.289$ \\
\hline $\mathrm{HCV}$ & 0.007 & 0.734 & $0.586-0.920$ & 0.310 & 0.094 & $0.744-1.099$ \\
\hline Child- Pugh score & 0.609 & 1.034 & $0.910-1.15$ & 0.002 & 1.204 & $1.070-1.354$ \\
\hline MELD score & 0.089 & 1.031 & $0.995-1.067$ & 0.121 & 1.018 & $0.995-1.042$ \\
\hline \multicolumn{7}{|l|}{$\mathrm{BCLC}$ stage } \\
\hline 0 & Ref. & & & Ref. & & \\
\hline A & 0.318 & 1.295 & $0.780-2.148$ & 0.405 & 1.191 & $0.790-1.795$ \\
\hline B & 0.041 & 1.764 & $1.024-3.040$ & 0.015 & 1.729 & $1.111-2.689$ \\
\hline C & 0.006 & 2.168 & $1.255-3.745$ & 0.005 & 1.832 & $1.20 \mathrm{I}-2.794$ \\
\hline $\mathrm{D}$ & 0.031 & 2.263 & $1.076-4.760$ & 0.024 & 1.941 & $1.090-3.456$ \\
\hline \multicolumn{7}{|l|}{ Hepatic encephalopathy } \\
\hline None & Ref. & & & Ref. & & \\
\hline Gr I-2 & 0.005 & 2.356 & $1.298-4.276$ & 0.253 & 0.702 & $0.382-1.288$ \\
\hline Gr 3-4 & 0.072 & 2.116 & $0.936-4.786$ & 0.359 & 0.868 & $0.756-1.112$ \\
\hline AFP & & & & 0.022 & 1.380 & $0.993-2.213$ \\
\hline PIVKA & & & & $<0.001$ & 1.259 & $0.893-1.983$ \\
\hline \multicolumn{7}{|l|}{ Treatment } \\
\hline Surgical resection & Ref. & & & Ref. & & \\
\hline Local ablation therapy & 0.003 & 2.830 & $1.411-5.677$ & 0.023 & 1.593 & $1.067-2.379$ \\
\hline Transarterial therapy & $<0.001$ & 3.556 & $1.934-6.539$ & $<0.001$ & 2.701 & $1.994-3.658$ \\
\hline Systemic chemotherapy & 0.021 & 11.68 & $1.460-93.506$ & $<0.001$ & 9.287 & $6.123-14.085$ \\
\hline Radiation therapy & $<0.001$ & 16.307 & $6.020-44.173$ & $<0.001$ & 4.659 & $2.20 I-9.860$ \\
\hline No treatment & $\mathrm{N} / \mathrm{A}$ & & & $<0.001$ & 7.213 & $5.107-10.186$ \\
\hline$<$ Unknown & $<0.001$ & 6.481 & $3.438-12.218$ & $<0.001$ & 6.673 & $3.212-13.865$ \\
\hline
\end{tabular}

Abbreviations: BMI, body mass index; HBV, hepatitis B; HCV, hepatitis C; AFP, alpha-fetoprotein; PIVKA-II, proteins induced by vitamin K absence or antagonist-II; MELD, model for end-stage liver disease; BCLC, Barcelona clinic liver cancer; BMI, body mass index.

and TACE are effective modalities for treating HCC in elderly patients. However, clinicians should not overlook the procedure-related complications, such as infections and bleeding, associated with RFA and vessel injury owing to age related atherosclerosis and contrast induced renal dysfunction in TACE. ${ }^{35}$

There are some limitations of this study. First, data were not available regarding liver transplantation, which is being implemented as a fundamental treatment for HCC. Second, data on specific findings, such as HCC location or surgical method and operation type, were also not available. Third, the data for disease-free survival were incomplete. Fourth, data for the treatment method and cause of HCC were incomplete for several patients included in this study. A more comprehensive national database, which includes detailed findings for all patients, is needed for conducting similar studies in the future.

As advanced countries move towards a super-aged society, the number of elderly patients with HCC is expected to increase. With the recent improvement in the outcomes of antiviral treatment, the mortality rate associated with liver cirrhosis is likely to decrease. As the rate of chronic viral infections of the liver increases among elderly patients, the rate of $\mathrm{HCC}$ will also increase. Clinicians must be aware of the balance between survival benefits and postoperative complications and exacerbation of comorbidities, when considering aggressive treatment for elderly patients with HCC. Aggressive treatments, such as surgical resection, can be performed in elderly patients only after 
the careful and comprehensive evaluation of the patient's condition.

\section{Ethical Statement}

All data included in these analyses were collected from the NCC and KLCA. The data accessed complied with relevant data protection and privacy regulations. Informed consent was obtained by the NCC and KLCA, and the collection of data was approved by each participating medical center or institution. This study was approved by the internal review board of Severance Hospital (IRB No. 4-2018-0354) and was conducted according to the principles of the Declaration of Helsinki.

\section{Acknowledgment}

The database used in this study was provided by the Korean Central Cancer Registry, Ministry of Health and Welfare, South Korea as well as the Korean Liver Cancer Association.

This abstract for this paper was presented at American Association for the Study of Liver Disease (AASLD) conference 2019 (Poster number 362). (https://aasldpubs. onlinelibrary.wiley.com/doi/full/10.1002/hep.30941)

\section{Author Contributions}

Seoung Yoon Rho, and Hyun Woong Lee have complete access to all data included in the study and are responsible for the integrity of the data and accuracy of analyses.

Study concept and design: Kyung Sik Kim

Acquisition of data: Seoung Yoon Rho, Do Young Kim and Hyun Woong Lee

Analysis and interpretation of data: Seoung Yoon Rho,

Do Young Kim, and Hyun Woong Lee

Manuscript preparation: Seoung Yoon Rho, and Hyun Woong Lee

Statistical analysis: Seoung Yoon Rho, and Hyun Woong Lee

All authors made substantial contributions to conception and design, acquisition of data, or analysis and interpretation of data; took part in drafting the article or revising it critically for important intellectual content; agreed to submit to the current journal; gave final approval of the version to be published; and agree to be accountable for all aspects of the work.

\section{Funding}

This research was supported by a grant of the Scientific Research Fund of the Korean Liver Cancer Association.

\section{Disclosure}

The authors have no conflicts of interest to declare for this work.

\section{References}

1. Fitzmaurice C, Akinyemiju TF, Al Lami FH, et al. Global, Regional, and National Cancer Incidence, Mortality, Years of Life Lost, Years Lived With Disability, and Disability-Adjusted Life-Years for 29 Cancer Groups, 1990 to 2016: a Systematic Analysis for the Global Burden of Disease Study. JAMA Oncol. 2018;4(11):1553-1568. doi:10.1001/jamaoncol.2018.2706

2. Bosch FX, Ribes J, Díaz M, Cléries R. Primary liver cancer: worldwide incidence and trends. Gastroenterology. 2004;127(5 Suppl 1): S5-s16. doi:10.1053/j.gastro.2004.09.011

3. Kim BH, Park J-W. Epidemiology of liver cancer in South Korea. Clin Mol Hepatol. 2018;24(1):1-9. doi:10.3350/cmh.2017.0112

4. Hyun KR, Kang S, Lee S. Population aging and healthcare expenditure in Korea. Health Econ. 2016;25(10):1239-1251. doi:10.1002/hec.3209

5. Kim BK, Kim DY, Han K-H, Seong J. Changes in real-life practice for hepatocellular carcinoma patients in the Republic of Korea over a 12-year period: a nationwide random sample study. PLoS One. 2019;14(10):e0223678. doi:10.1371/journal.pone.0223678

6. Asahina Y, Tsuchiya K, Tamaki N, et al. Effect of aging on risk for hepatocellular carcinoma in chronic hepatitis $\mathrm{C}$ virus infection. Hepatology. 2010;52(2):518-527. doi:10.1002/hep.23691

7. Cho SJ, Yoon JH, Hwang SS, Lee HS. Do young hepatocellular carcinoma patients with relatively good liver function have poorer outcomes than elderly patients? J Gastroenterol Hepatol. 2007;22 (8):1226-1231. doi:10.1111/j.1440-1746.2007.04914.x

8. Ebrahim S. The ageing \& development report 1999: poverty, independence \& the world's older people. BMJ. 2000;321(7259):517. doi:10.1136/bmj.321.7259.517

9. Hung AK, Guy J. Hepatocellular carcinoma in the elderly: meta-analysis and systematic literature review. World J Gastroenterol. 2015;21 (42):12197-12210. doi:10.3748/wjg.v21.i42.12197

10. Katsuta E, Tanaka S, Mogushi K, et al. Age-related clinicopathologic and molecular features of patients receiving curative hepatectomy for hepatocellular carcinoma. Am J Surg. 2014;208(3):450-456. doi:10.1016/j.amjsurg.2014.01.015

11. Iida H, Kaibori M, Matsui K, Ishizaki M, Kon M. Assessing the feasibility of clinicopathological features of hepatic resection for hepatocellular carcinoma in patients over 80 years of age. Mol Clin Oncol. 2017;6(1):29-38. doi:10.3892/mco.2016.1079

12. Nozawa A, Kubo S, Takemura S, et al. Hepatic resection for hepatocellular carcinoma in super-elderly patients aged 80 years and older in the first decade of the 21st century. Surg Today. 2015;45 (7):851-857. doi:10.1007/s00595-014-0994-1

13. Yamada S, Shimada M, Miyake H, et al. Outcome of hepatectomy in super-elderly patients with hepatocellular carcinoma. Hepatol Res. 2012;42(5):454-458. doi:10.1111/j.1872-034X.2011.00952.x

14. Lee CR, Lim JH, Kim SH, et al. A comparative analysis of hepatocellular carcinoma after hepatic resection in young versus elderly patients. J Gastrointest Surg. 2012;16(9):1736-1743. doi:10.1007/ s11605-012-1966-7

15. Lee SH, Choi HC, Jeong SH, et al. Hepatocellular carcinoma in older adults: clinical features, treatments, and survival. J Am Geriatr Soc. 2011;59(2):241-250. doi:10.1111/j.1532-5415.2010.03273.x

16. Seo JH, Kim DH, Cho E, et al. Characteristics and outcomes of extreme elderly patients with hepatocellular carcinoma in South Korea. In Vivo (Brooklyn). 2019;33(1):145-154. doi:10.21873/invivo.11451

17. Kinoshita A, Koike K, Nishino H. Clinical features and prognosis of elderly patients with hepatocellular carcinoma not indicated for surgical resection. Geriatr Gerontol Int. 2017;17(2):189-201. doi:10.1111/ggi.12747 
18. Kim DY, Kim IH, Jeong SH, et al. A nationwide seroepidemiology of hepatitis C virus infection in South Korea. Liver Int. 2013;33 (4):586-594. doi:10.1111/liv.12108

19. Paradis V, Zalinski S, Chelbi E, et al. Hepatocellular carcinomas in patients with metabolic syndrome often develop without significant liver fibrosis: a pathological analysis. Hepatology. 2009;49 (3):851-859. doi:10.1002/hep.22734

20. Satyanarayana A, Manns MP, Rudolph KL. Telomeres and telomerase: a dual role in hepatocarcinogenesis. Hepatology. 2004;40 (2):276-283. doi:10.1002/hep.20308

21. Plentz RR, Park YN, Lechel A, et al. Telomere shortening and inactivation of cell cycle checkpoints characterize human hepatocarcinogenesis. Hepatology. 2007;45(4):968-976. doi: $10.1002 /$ hep. 21552

22. Waki K, Aikata H, Katamura Y, et al. Percutaneous radiofrequency ablation as first-line treatment for small hepatocellular carcinoma: results and prognostic factors on long-term follow up. $J$ Gastroenterol Hepatol. 2010;25(3):597-604. doi:10.1111/j.14401746.2009.06125.x

23. Kang TW, Kim JM, Rhim H, et al. Small hepatocellular carcinoma: radiofrequency ablation versus nonanatomic resection-propensity score analyses of long-term outcomes. Radiology. 2015;275 (3):908-919. doi:10.1148/radiol.15141483

24. Izumi N, Hasegawa $\mathrm{K}$, Nishioka $\mathrm{Y}$, et al. A multicenter randomized controlled trial to evaluate the efficacy of surgery vs. radiofrequency ablation for small hepatocellular carcinoma (SURF trial). J Clin Oncol. 2019;37(15_suppl):4002. doi:10.1200/ JCO.2019.37.15_suppl.4002

25. Li L, Zhang J, Liu X, Li X, Jiao B, Kang T. Clinical outcomes of radiofrequency ablation and surgical resection for small hepatocellular carcinoma: a meta-analysis. J Gastroenterol Hepatol. 2012;27 (1):51-58. doi:10.1111/j.1440-1746.2011.06947.x

26. Xu XL, Liu XD, Liang M, Luo BM. Radiofrequency ablation versus hepatic resection for small hepatocellular carcinoma: systematic review of randomized controlled trials with meta-analysis and trial sequential analysis. Radiology. 2018;287(2):461-472. doi:10.1148/ radiol.2017162756
27. Korean Liver Cancer Association; National Cancer Center. 2018 Korean Liver Cancer Association-National Cancer Center Korea Practice Guidelines for the Management of Hepatocellular Carcinoma. Gut Liver. 2019;13(3):227-299. doi:10.5009/gnl19024

28. Kim JM, Cho BI, Kwon CH, et al. Hepatectomy is a reasonable option for older patients with hepatocellular carcinoma. Am J Surg. 2015;209(2):391-397. doi:10.1016/j.amjsurg.2013.06.010

29. Kishida N, Hibi T, Itano O, et al. Validation of hepatectomy for elderly patients with hepatocellular carcinoma. Ann Surg Oncol. 2015;22(9):3094-3101. doi:10.1245/s10434-014-4350-x

30. Kaibori M, Yoshii K, Yokota I, et al. Impact of advanced age on survival in patients undergoing resection of hepatocellular carcinoma: report of a Japanese Nationwide Survey. Ann Surg. 2017. doi:10.1097/sla.0000000000002526

31. Liu PH, Hsu CY, Lee YH, et al. Uncompromised treatment efficacy in elderly patients with hepatocellular carcinoma: a propensity score analysis. Medicine (Baltimore). 2014;93(28):e264. doi:10.1097/ md.0000000000000264

32. Takahashi H, Mizuta T, Kawazoe S, et al. Efficacy and safety of radiofrequency ablation for elderly hepatocellular carcinoma patients. Hepatol Res. 2010;40(10):997-1005. doi:10.1111/j.1872034X.2010.00713.x

33. Yau T, Yao TJ, Chan P, et al. The outcomes of elderly patients with hepatocellular carcinoma treated with transarterial chemoembolization. Cancer. 2009;115(23):5507-5515. doi:10.1002/ cncr. 24636

34. Mirici-Cappa F, Gramenzi A, Santi V, et al. Treatments for hepatocellular carcinoma in elderly patients are as effective as in younger patients: a 20-year multicentre experience. Gut. 2010;59(3):387-396. doi:10.1136/gut.2009.194217

35. Nishikawa H, Kimura T, Kita R, Osaki Y. Treatment for hepatocellular carcinoma in elderly patients: a literature review. $J$ Cancer. 2013;4(8):635-643. doi:10.7150/jca.7279
Journal of Hepatocellular Carcinoma

\section{Publish your work in this journal}

The Journal of Hepatocellular Carcinoma is an international, peerreviewed, open access journal that offers a platform for the dissemination and study of clinical, translational and basic research findings in this rapidly developing field. Development in areas including, but not limited to, epidemiology, vaccination, hepatitis therapy, pathology and molecular tumor classification and prognostication are all considered for publication. The manuscript management system is completely online and includes a very quick and fair peer-review system, which is all easy to use. Visit http://www.dovepress.com/ testimonials.php to read real quotes from published authors. 